\title{
Pusillimonas noertemannii gen. nov., sp. nov., a new member of the family Alcaligenaceae that degrades substituted salicylates
}

\author{
Correspondence \\ Andreas Stolz \\ Andreas.Stolz@imb. \\ Uni-Stuttgart.de
}

\author{
Andreas Stolz, ${ }^{1}$ Sibylle Bürger, ${ }^{1}$ Andrea Kuhm, ${ }^{1}$ Peter Kämpfer ${ }^{2}$ \\ and Hans-Jürgen Busse ${ }^{3}$ \\ ${ }^{1}$ Institut für Mikrobiologie, Universität Stuttgart, Allmandring 31, 70569 Stuttgart, Germany \\ ${ }^{2}$ Institut für Angewandte Mikrobiologie, Justus-Liebig-Universität Giessen, Heinrich-Buff-Ring \\ 26-32 (IFZ), D-35392 Giessen, Germany \\ ${ }^{3}$ Institut für Bakteriologie, Mykologie und Hygiene, Veterinärmedizinische Universität Wien, \\ Veterinärplatz 1, A-1210 Wien, Austria
}

Strain $\mathrm{BN}^{\mathrm{T}}$ had previously been isolated from a 6aminonaphthalene-2-sulphonate (6A2NS)-degrading mixed bacterial culture that was originally enriched from water from the River Elbe in Germany. It was subsequently demonstrated that the strain mineralized 5-aminosalicylate (5AS), which was formed as an intermediate compound in the metabolism of 6A2NS in the mixed culture (Nörtemann et al., 1986). The metabolism of 5AS by strain $\mathrm{BN} 9^{\mathrm{T}}$ was analysed in detail and it was shown that the strain converted 5AS by an extraordinary ring-fission dioxygenase to a non-aromatic aminated ring-fission product (Stolz et al., 1992; Stolz \& Knackmuss, 1993a). The strain also degraded 3-aminobenzoate via 5 AS and 2,3-, 2,4- and

Published online ahead of print on 3 December 2004 as DOI 10.1099/ ijs.0.63466-0.

The GenBank/EMBL/DDBJ accession number for the 16S rRNA gene sequence of Pusillimonas noertemannii $\mathrm{BN9}^{\top}$ is AY695828.

Two-dimensional chromatograph of polar lipids of different members of the Alcaligenaceae is available as supplementary material in IJSEM Online. 2,5-dihydroxybenzoate via different degradative pathways (Russ et al., 1994; Stolz, 1989; Stolz \& Knackmuss, 1993b).

The organism was originally tentatively identified as a pseudomonad, but an analysis of its quinone system $(\mathrm{Q}-8)$, polyamine pattern (mainly putrescine, spermidine and 2hydroxyputrescine) and a 158 bp sequence of its $16 \mathrm{~S}$ rRNA suggested that the strain was closely related to the genus Alcaligenes (Busse et al., 1992). Here we report a detailed characterization of strain $\mathrm{BN}^{\mathrm{T}}$.

Strain $\mathrm{BN}^{\mathrm{T}}$ showed only weak growth on all complex [Luria-Bertani (LB) and nutrient broth (NB)] or mineral media tested. Generally, the best growth was observed on chocolate blood agar (Columbia agar base; Oxoid CM331, prepared as recommended by the manufacturer, after cooling to $45^{\circ} \mathrm{C}$, supplemented with $10 \%$ defibrinated sheep blood and boiled) after $3-4$ days incubation at $37^{\circ} \mathrm{C}$, which resulted in a colony diameter of approximately 2-3 mm. Growth was slightly slower on blood agar (Oxoid 331 , prepared as described above but supplemented with $5 \%$ defibrinated sheep blood and without boiling) under 
the same conditions. On complex media such as $\mathrm{NB}$ or peptone yeast extract (PYE; $0.3 \%$ yeast extract, $0.3 \%$ peptone, $1.5 \%$ agar, $\mathrm{pH} 7 \cdot 2$ ) the colonies reached a diameter of about $1-2 \mathrm{~mm}$ within $5-6$ days at $30^{\circ} \mathrm{C}$. The colonies were brownish, circular with an entire margin. Growth at $37^{\circ} \mathrm{C}$ was slightly faster than at $30^{\circ} \mathrm{C}$. In the presence of increased $\mathrm{CO}_{2}$ concentrations $(5 \%)$ no visible differences compared with growth at normal $\mathrm{O}_{2}$ and $\mathrm{CO}_{2}$ pressures were observed (at $\left.37^{\circ} \mathrm{C}\right)$. Other growth characteristics are given in the species description below.

The $16 \mathrm{~S}$ rRNA gene sequence of strain $\mathrm{BN}^{\mathrm{T}}$, containing a continuous sequence of $1524 \mathrm{bp}$ (positions 46-1502 according to the Escherichia coli numbering scheme; Brosius et al., 1978), was used to search the GenBank library. The results of the sequence comparisons demonstrated that strain $\mathrm{BN9}^{\mathrm{T}}$ was indeed most closely related to different members within the Alcaligenaceae. Phylogenetic trees were generated by using the maximum-parsimony, maximumlikelihood and neighbour-joining methods from the PHYLIP program package (Felsenstein, 1993). In these trees, strain BN9 ${ }^{\mathrm{T}}$ grouped separately from the clades formed by the genera Achromobacter, Alcaligenes, Bordetella and Kerstersia. A closer relationship was suggested by the sequence comparison programs between strain $\mathrm{BN}^{\mathrm{T}}$ and members of the genera Taylorella, Pelistega and Advenella (Fig. 1). Furthermore, all phylogenetic trees suggested that Alcaligenes faecalis DSM $30030^{\mathrm{T}}$ and Alcaligenes defragrans DSM $12141^{\mathrm{T}}$ (Foss et al., 1998) do not form a coherent group within the clade and therefore presumably do not belong to the same genus.
The fatty acid profile of strain $\mathrm{BN} 9^{\mathrm{T}}$ showed many of the characteristics also found in species of the genera Alcaligenes, Achromobacter, Bordetella, Pigmentiphaga, Kerstersia, Oligella, Taylorella and Pelistega (Table 1; Vandamme et al., 1996; Busse \& Stolz, 2004). However, the presence of the major compound $\mathrm{C}_{19: 0}$ cyclo $\omega 8 \mathrm{c}$ was specific for strain

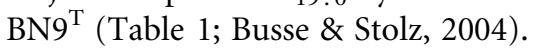

The polar lipid compositions of $\mathrm{BN}^{\mathrm{T}}$, Alcaligenes faecalis DSM $30030^{\mathrm{T}}$, Achromobacter xylosoxidans KM534 ${ }^{\mathrm{T}}$, Achromobacter denitrificans DSM $30026^{\mathrm{T}}$ and Alcaligenes defragrans DSM $12141^{\mathrm{T}}$ are shown in Table 2 and Fig. A (supplementary material, IJSEM Online). Each of the five strains showed a distinct polar lipid profile, including the known polar lipids diphosphatidylglycerol, phosphatidylglycerol and phosphatidylethanolamine as well as several unknown aminophospholipids, aminolipids, phospholipids and further polar lipids. The most pronounced characteristics of strain $\mathrm{BN}^{\mathrm{T}}$ were the presence of almost equal amounts of diphosphatidylglycerol, phosphatidylglycerol, phosphatidylethanolamine and rather high amounts of the two characteristic aminolipids AL1 and AL2. In addition to the presence and absence of several minor lipids these characteristics clearly distinguished strain $\mathrm{BN}^{\mathrm{T}}$ from the other four strains. In contrast to a previous report of Yabuuchi et al. (1995), who described for Alcaligenes faecalis EY $1056^{\mathrm{T}}$ only the presence of phosphatidylethanolamine (54\%), phosphatidylglycerol (26\%) and ornithine lipid OL-1 (20\%), in the present study diphosphatidylglycerol and several unknown aminophospholipids, phospholipids, aminolipids and polar lipids were also detected [see

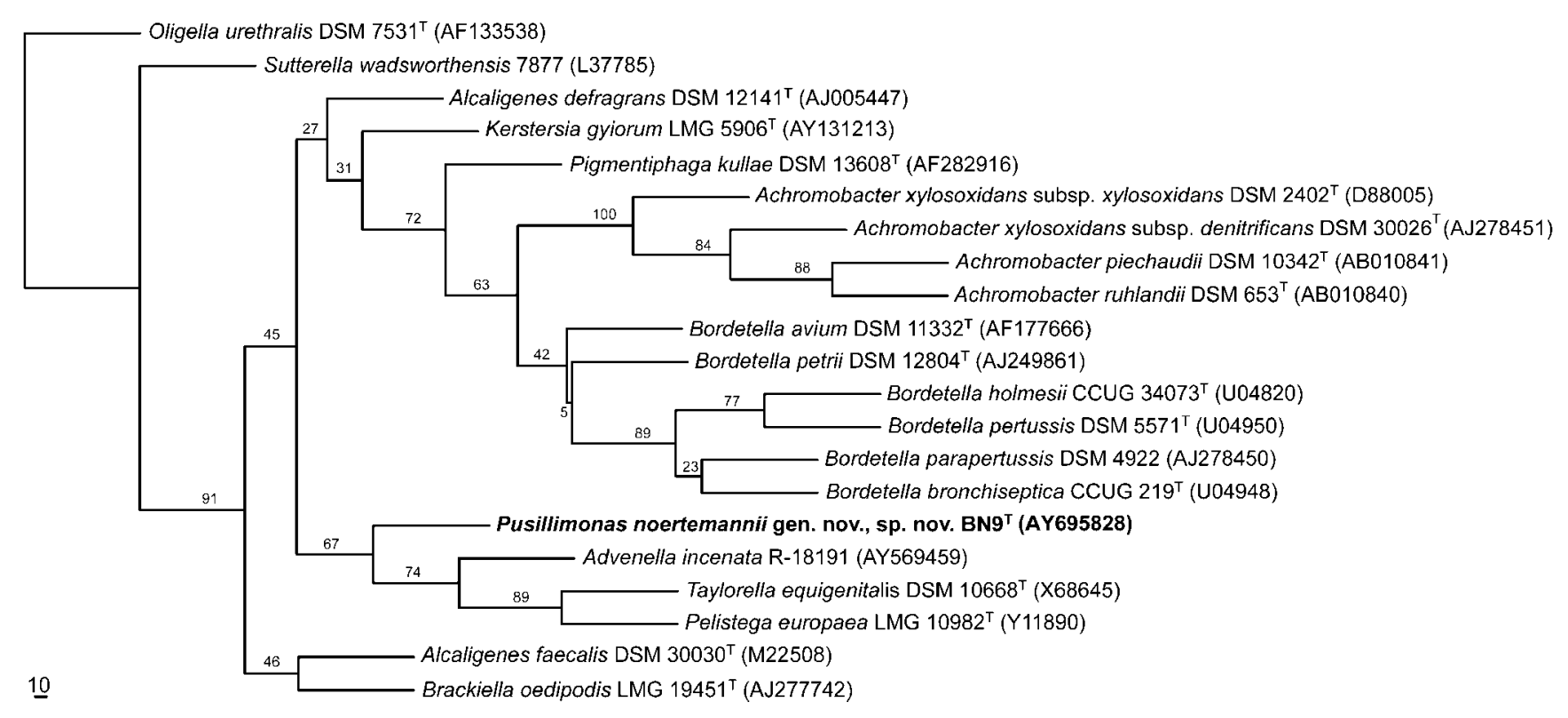

Fig. 1. Phylogenetic tree showing the relationship between strain $B N 9^{\top}$ and selected strains from other bacterial taxa. The tree was constructed by using the maximum-parsimony method and the program TreeView. Bootstrap values based on 100 replications are given as percentages at the branching points. Bar, a difference of approximately $10 \mathrm{nt}$. 
Table 1. Relative fatty acid compositions of strain $B N 9^{\top}$ in comparison to species of the genera Alcaligenes, Achromobacter, Pigmentiphaga and Kerstersia

1, $\mathrm{BN}^{\mathrm{T}}$; 2, Alcaligenes faecalis LMG $1229^{\mathrm{T}}$ (data from Coenye et al., 2003a); 3, Alcaligenes defragrans DSM $12141^{\mathrm{T}}$ (this study); 4, Achromobacter (Coenye et al., 2003a, b); 5, Pigmentiphaga kullae DSM $13608^{\mathrm{T}}$ (Blümel et al., 2001); 6, Kerstersia gyiorum LMG $5906^{\mathrm{T}}$ (Coenye et al., 2003a). Data given for the genus Achromobacter indicate the range of values described for Achromobacter xylosoxidans, Achromobacter denitrificans, Achromobacter piechaudii, Achromobacter insolitus and Achromobacter spanius (Coenye et al., 2003a, b). -, Not present; 3-OH $\mathrm{C}_{10: 0}$, 3-hydroxydecanoic acid; $\mathrm{C}_{12: 0}$, dodecanoic acid = lauric acid; 2-OH $\mathrm{C}_{12: 0}$, 2-hydroxydodecanoic acid; $\mathrm{C}_{14: 0}$, tetradecanoic acid $=$ myristic acid; $2-\mathrm{OH} \mathrm{C}_{14: 0}, 2$ hydroxytetradecanoic acid; 3-OH $\mathrm{C}_{14: 0}, 3$-hydroxytetradecanoic acid; $\mathrm{C}_{16: 1} \omega 7 c$, cis-9-hexadecenoic acid = palmitinoleic acid; $\mathrm{C}_{16: 0}$, hexadecanoic acid = palmitic acid; $\mathrm{C}_{17: 0}$ cyclo, $\Delta$-cis-9,10-methylenehexadecanoic acid; 2-OH $\mathrm{C}_{16: 0}$, 2-hydroxyhexadecanoic acid; $\mathrm{C}_{18: 1} \omega 7 c$, cis-11-octadecenoic acid $=$ vaccenic acid; $\mathrm{C}_{18: 0}$, octadecanoic acid=stearic acid; $\mathrm{C}_{19: 0}$ cyclo $\omega 8 c, \Delta$-cis-11,12-methyleneoctadecanoic acid; $\mathrm{Tr}$, trace amounts present. The fatty acid profiles of strains $\mathrm{BN}^{\mathrm{T}}$ and Alcaligenes defragrans DSM $12141^{\mathrm{T}}$ were determined according to Kämpfer \& Kroppenstedt (1996). Values characteristic for strain $\mathrm{BN} 9^{\mathrm{T}}$ are given in bold type.

\begin{tabular}{|c|c|c|c|c|c|c|}
\hline Characteristic & 1 & 2 & 3 & 4 & 5 & 6 \\
\hline $\mathrm{C}_{10: 0}$ & $\operatorname{Tr}$ & - & $\operatorname{Tr}$ & - & - & - \\
\hline Summed feature 1 & 1 & & 3 & & & \\
\hline $\mathrm{C}_{12: 0}$ & 4 & 2 & 6 & $\operatorname{Tr}$ & - & - \\
\hline $2-\mathrm{OH} \mathrm{C} 12: 0$ & 3 & 2 & - & $3-5$ & - & $\operatorname{Tr}$ \\
\hline $\mathrm{C}_{13: 1}$ AT $12-13$ & $\operatorname{Tr}$ & - & - & - & - & - \\
\hline Summed feature 2 & $8^{\star}$ & $10^{*}$ & 5 & $9-13^{*}$ & $5^{\star}$ & $12^{\star}$ \\
\hline Summed feature 3 & $\operatorname{Tr} \dagger$ & $7 \dagger$ & 28 & $5-18$ & - & $4 \dagger$ \\
\hline $\mathrm{C}_{16: 0}$ & 19 & 37 & 32 & $29-40$ & 40 & 34 \\
\hline $\mathrm{C}_{17: 0}$ cyclo & 31 & 29 & 7 & $17-32$ & 22 & 24 \\
\hline $2-\mathrm{OH} \mathrm{C} 16: 0$ & $\operatorname{Tr}$ & - & - & $\operatorname{Tr}-2 \cdot 4$ & 5 & - \\
\hline $3-\mathrm{OH} \mathrm{C} \mathrm{C}_{16: 0}$ & $\operatorname{Tr}$ & - & - & - & - & - \\
\hline $\mathrm{C}_{18: 1} \omega 7 c$ & $\operatorname{Tr}$ & 4 & $18 \ddagger$ & $2-5$ & $10 \$$ & 11 \\
\hline $\mathrm{C}_{18: 1} \omega 7 c 11$ methyl & $\operatorname{Tr}$ & - & - & - & - & - \\
\hline $\mathrm{C}_{18: 0}$ & 3 & $\operatorname{Tr}$ & - & 2 & - & 3 \\
\hline $\mathrm{C}_{19: 0}$ iso & $\operatorname{Tr}$ & - & $\operatorname{Tr}$ & - & - & - \\
\hline $\mathrm{C}_{19: 0}$ cyclo $\omega 8 \mathrm{c}$ & 27 & $\operatorname{Tr}$ & $\operatorname{Tr}$ & $\operatorname{Tr}$ & 12 & 2 \\
\hline $\mathrm{C}_{20: 2} \omega 6,9 c$ & $\operatorname{Tr}$ & - & $\operatorname{Tr}$ & - & - & - \\
\hline
\end{tabular}

${ }^{*} \mathrm{C}_{16: 1}$ iso I and/or 3-OH $\mathrm{C}_{14: 0}$.

$\dagger \mathrm{C}_{16: 1} \omega 7 c$ and/or 2-OH $\mathrm{C}_{15: 0}$ iso.

$\ddagger$ Given as $\mathrm{C}_{18: 1} \omega 7 \mathrm{c}$ or $\mathrm{C}_{18: 1} \omega 9$ t.

Given as summed feature $7\left(\mathrm{C}_{18: 1} \omega 7 c, \mathrm{C}_{18: 1} \omega 9 t\right.$ and/or $\left.\mathrm{C}_{18: 1} \omega 12 t\right)$.

supplementary Fig. A(II) in IJSEM Online]. Achromobacter denitrificans DSM $30026^{\mathrm{T}}$ and Achromobacter xylosoxidans $\mathrm{KM}_{543^{\mathrm{T}}}$ were more closely related in their polar lipid profile [see supplementary Fig. A(IV) and (V) in IJSEM Online] to each other than to any other strain studied here, although they differed with regard to the presence of phospholipid PL6 and aminophospholipid 3 and with regard to the
Table 2. Polar lipid profiles in different members of the Alcaligenaceae

1, Alcaligenes faecalis DSM $30030^{\mathrm{T}} ; 2$, Achromobacter xylosoxidans KM543 ${ }^{\mathrm{T}} ; 3$, Achromobacter denitrificans DSM $30026^{\mathrm{T}}$; 4, Alcaligenes defragrans DSM $12141^{\mathrm{T}} ; 5, \mathrm{BN} 9^{\mathrm{T}}$. DPG, diphosphatidylglycerol; PG, phosphatidylglycerol; PE, phosphatidylethanolamine; AL1-7, unknown aminolipids; PL1-6, unknown phospholipids; APL1-5, unknown aminophospholipids; L1-8, unknown polar lipids. ++++ , Major amounts; +++ , moderate amounts; ++ , minor amounts; + , trace amounts; - , not detected.

\begin{tabular}{|c|c|c|c|c|c|}
\hline $\begin{array}{l}\text { Polar } \\
\text { lipid }\end{array}$ & 1 & 2 & 3 & 4 & 5 \\
\hline $\mathrm{PE}$ & ++++ & ++++ & ++++ & ++++ & ++++ \\
\hline PG & +++ & ++ & ++ & +++ & ++++ \\
\hline DPG & +++ & +++ & +++ & ++ & ++++ \\
\hline AL1 & ++ & ++ & ++ & ++ & +++ \\
\hline AL2 & - & + & + & - & ++++ \\
\hline AL3 & - & - & - & ++ & - \\
\hline AL4 & ++ & - & - & +++ & - \\
\hline AL5 & + & - & - & + & - \\
\hline AL6 & + & + & + & ++ & - \\
\hline AL7 & + & - & - & - & - \\
\hline PL1 & - & - & - & + & - \\
\hline PL2 & + & - & - & + & + \\
\hline PL3 & - & +++ & + & - & - \\
\hline PL4 & - & ++ & + & - & - \\
\hline PL5 & + & + & + & - & - \\
\hline PL6 & - & + & - & - & - \\
\hline APL1 & + & ++ & + & + & - \\
\hline APL2 & - & - & - & + & - \\
\hline APL3 & - & - & + & - & - \\
\hline APL4 & + & - & - & - & + \\
\hline APL5 & + & - & - & - & - \\
\hline $\mathrm{L} 1$ & - & - & - & - & + \\
\hline L2 & - & - & - & - & + \\
\hline L3 & + & + & + & + & ++ \\
\hline L4 & - & - & - & - & + \\
\hline L5 & - & - & - & + & - \\
\hline L6 & - & - & - & + & - \\
\hline L7 & - & - & - & + & - \\
\hline L8 & - & - & - & - & - \\
\hline
\end{tabular}

relative proportion of phospholipid PL3. The differences observed between Achromobacter xylosoxidans $\mathrm{KM} 543^{\mathrm{T}}$ and Achromobacter denitrificans DSM $30026^{\mathrm{T}}$ supported the view of Coenye et al. (2003a) that the two strains represent different species and not two subspecies of Achromobacter xylosoxidans as favoured by Yabuuchi et al. (1998). The polar lipid profile of Alcaligenes defragrans DSM $12141^{\mathrm{T}}$ showed several unique characteristics [Table 2 and see Supplementary Fig. A(III), IJSEM Online] that might be useful for a future reclassification of this species within a novel genus of the family Alcaligenaceae.

Strain $\mathrm{BN} 9^{\mathrm{T}}$ did not produce acids aerobically from various 
sugars and sugar alcohols tested. Of various $p$-nitrophenyl and $p$-nitroaniline derivatives only L-alanine- $p$-nitroanilide was hydrolysed (method according to Kämpfer et al., 1991). Only simple aliphatic and aromatic organic acids were utilized as sources of carbon and energy (for details, see species description below).

The family Alcaligenaceae currently consists of the recognized affiliated genera Alcaligenes, Achromobacter, Advenella, Bordetella and Pigmentiphaga. However, according to 16S rRNA gene sequence comparisons the genera Brackiella, Kerstersia, Oligella, Pelistega, Sutterella and Taylorella should also be included in this family (Busse \& Stolz, 2004; Willems et al., 2002; Coenye et al., 2005). Phylogenetically, these genera form together with strain $\mathrm{BN}^{\mathrm{T}}$ a homogeneous cluster separate from other taxa within the 'Betaproteobacteria'. The affiliation of strain $\mathrm{BN} 9^{\mathrm{T}}$ to this family was unambiguously demonstrated by $16 \mathrm{~S}$ rRNA gene sequence comparisons and phylogenetic analyses. This affiliation was also confirmed based on the presence of ubiquinone Q-8, putrescine and 2-hydroxyputrescine in the polyamine pattern (Busse \& Auling, 1988; Busse et al., 1992), and large amounts of 16:0 and 17:0 cyclo fatty acids present in strain $\mathrm{BN}^{\mathrm{T}}$.

Two subgroups can be defined within the Alcaligenaceae based on the $\mathrm{G}+\mathrm{C}$ content of their genomic DNA. Members of the genera Alcaligenes, Achromobacter and Pigmentiphaga have $\mathrm{G}+\mathrm{C}$ contents ranging from 54 to $69 \mathrm{~mol} \%$. In contrast, members of the genera Oligella, Taylorella and Pelistega have only relatively low $\mathrm{G}+\mathrm{C}$ contents of $36 \cdot 5-47 \cdot 5 \mathrm{~mol} \%$ (Busse \& Stolz, 2004). The G+C content of strain $\mathrm{BN}^{\mathrm{T}}$ was previously determined as $61 \cdot 8 \pm 0 \cdot 2 \mathrm{~mol} \%$ (Busse et al., 1992) and thus would clearly suggest a closer relationship of strain $\mathrm{BN}^{\mathrm{T}}$ with the freeliving members of the genera Alcaligenes, Achromobacter and Pigmentiphaga than with the genera Oligella, Taylorella and Pelistega. This was in clear contrast to the results of the 16S rRNA gene sequence comparisons, which placed strain $\mathrm{BN}^{\mathrm{T}}$ close to the 'low-G $+\mathrm{C}$ members' of the Alcaligenaceae.

Thus, strain $\mathrm{BN}^{\mathrm{T}}$ could not be affiliated to any of the recognized genera within the family Alcaligenaceae. Furthermore, 16S rRNA gene sequence similarity values between strain $\mathrm{BN}^{\mathrm{T}}$ and all other described species within the family Alcaligenaceae were $\leqslant 96 \%$. It was previously stated that $16 \mathrm{~S}$ rRNA gene sequence similarity values among Achromobacter and Bordetella species are $97-98 \%$ and that it could be assumed from these values that the threshold for the differentiation of genera within the family Alcaligenaceae is at $<97 \%$ similarity (Blümel et al., 2001). Strain $\mathrm{BN}^{\mathrm{T}}$ was also clearly separated from all other members of the Alcaligenaceae based on the presence of trace amounts of 3-OH C $16: 0$ and by the large amounts of the fatty acid $\mathrm{C}_{19: 0}$ cyclo $\omega 8 c$. On the basis of these results, we consider that strain $\mathrm{BN}^{\mathrm{T}}$ is representative of a new taxon, for which the name Pusillimonas noertemannii gen. nov., sp. nov. is proposed.

\section{Description of Pusillimonas gen. nov.}

Pusillimonas (Pu.sil.li.mo'nas. L. adj. pusillus very small/ minute; Gr. fem n. monas unit/monad; N.L. fem. n. Pusillimonas very small monad/unicell, referring to the small size of cells and colonies of the type species).

Cells are Gram-negative, oxidase-positive and have an oxidative metabolism. G $+\mathrm{C}$ content of the DNA is $61 \cdot 8 \mathrm{~mol} \%$. Pusillimonas belongs to the family Alcaligenaceae. The major isoprenoid quinone is ubiquinone Q-8. Putrescine, spermidine and 2-hydroxyputrescine are the major polyamines. Major polar lipids are two unknown aminolipids, phosphatidylglycerol, diphosphatidylglycerol and phosphatidylethanolamine. Major non-polar fatty acids are $\mathrm{C}_{17: 0}$ cyclo, $\mathrm{C}_{19}$ : cyclo $\omega 8 c, \mathrm{C}_{16: 0}$ and summed feature $2\left(\mathrm{C}_{16: 1}\right.$ iso $\mathrm{I} / 3-$ $\mathrm{OH} \mathrm{C}_{14: 0}$ ).

The type species is Pusillimonas noertemannii.

\section{Description of Pusillimonas noertemannii sp. nov.}

Pusillimonas noertemannii (noer.te.mann'i.i. N.L. gen. n. noertemannii of Nörtemann, in honour of Bernd Nörtemann, who isolated this and various other bacterial strains that had extraordinary degradative abilities).

The description of the species is as given for the genus above. Cells are rod-shaped $(1-1.5 \mu \mathrm{m}$ in length and 0.5 $0.8 \mu \mathrm{m}$ in diameter). They are motile by means of polarly inserted flagella. On nutrient agar, colonies are brownish, circular and with an entire margin. Grows at 30, 37 and $42{ }^{\circ} \mathrm{C}$, but not at $4{ }^{\circ} \mathrm{C}$. L-Alanine- $p$-nitroanilide is hydrolysed on the basis of the method described by Kämpfer et al. (1991). The following compounds are not hydrolysed: $p$-nitrophenyl $\beta$-D-galactopyranoside, $p$-nitrophenyl $\beta$-D-glucuronide, $\quad p$-nitrophenyl $\alpha$-D-glucopyranoside, $p$-nitrophenyl $\beta$-D-glucopyranoside, $p$-nitrophenyl $\beta$-Dxylopyranoside, bis- $p$-nitrophenyl phosphate, bis- $p$-nitrophenyl-phenyl phosphonate, bis-p-nitrophenyl-phosphoryl choline, $\quad$-aniline- $p$-nitroanilide, $\quad \gamma$-L-glutamate- $p$ nitroanilide and L-proline- $p$-nitroanilide. The following compounds are used as sole source of carbon: acetate, propionate, DL-3-hydroxybutyrate, DL-lactate, 2-oxoglutarate, pyruvate and 4-hydroxybenzoate, on the basis of the method described by Kämpfer et al. (1991). The following compounds are not assimilated: $N$-acetylgalactosamine, $\mathrm{N}$-acetylglucosamine, L-arabinose, L-arbutin, D-cellobiose, D-fructose, D-galactose, gluconate, D-glucose, D-maltose, Dmannose, $\alpha$-D-melibiose, L-rhamnose, D-ribose, D-sucrose, salicin, D-trehalose, D-xylose, adonitol, $i$-inositol, maltitol, D-mannitol, D-sorbitol, putrescine, cis-aconitate, transaconitate, adipate, 4 -aminobutyrate, azelate, citrate, fumarate, glutarate, itaconate, L-malate, mesaconate, suberate, L-alanine, L-aspartate, L-histidine, L-leucine, L-ornithine, Lphenylalanine, L-serine, L-tryptophan, 3-hydroxybenzoate and phenylacetate. No acids are produced from glucose, lactose, sucrose, D-mannitol, dulcitol, salicin, adonitol, inositol, sorbitol, L-arabinose, raffinose, rhamnose, maltose, 
D-xylose, trehalose, cellobiose, methyl D-glucoside, erythritol, melibiose, D-arabitol or D-mannose. Quinone system, polyamine pattern and polar lipid profile are identical to those listed under the genus description. The fatty acid profile consists of $\mathrm{C}_{10: 0}$ (trace), $\mathrm{C}_{12: 0}(4 \cdot 4 \%), 2-\mathrm{OH} \mathrm{C} \mathrm{C}_{12: 0}$ $(3 \cdot 3 \%), C_{13: 1}$ AT $12-13$ (trace), summed feature $1\left(\mathrm{C}_{12: 0}\right.$ alde?) $(1 \cdot 2 \%)$, summed feature $4\left(\mathrm{C}_{16: 1}\right.$ iso I and/or 3-OH $\left.\mathrm{C}_{14: 0}\right)(8 \cdot 0 \%), \mathrm{C}_{16: 1} \omega 7 c$ (trace), $\mathrm{C}_{16: 0}(18 \cdot 5 \%), \mathrm{C}_{17: 0}$ cyclo (30.9\%), 2-OH C $16: 0$ (trace), 3-OH C $16: 0$ (trace), $\mathrm{C}_{18: 1} \omega 7 c$ (trace), $\mathrm{C}_{18: 1} \omega 7 c 11$ methyl (trace), $\mathrm{C}_{18: 0}(2 \cdot 5 \%), \mathrm{C}_{19: 0}$ iso $(0 \cdot 9 \%), \mathrm{C}_{19: 0}$ cyclo $\omega 8 c(26 \cdot 8 \%)$ and $\mathrm{C}_{20: 2} \omega 6,9 c$ (trace).

The type strain $\left(B N 9^{\mathrm{T}}=\right.$ DSM $\left.10065^{\mathrm{T}}=\mathrm{NCIMB} 14020^{\mathrm{T}}\right)$ was isolated from the River Elbe in Germany after enrichment of a mixed bacterial culture with 6-aminonaphthalene2-sulphonate. The $\mathrm{G}+\mathrm{C}$ content of the DNA of the type strain is $61 \cdot 8 \mathrm{~mol} \%\left(T_{\mathrm{m}}\right)$.

\section{Acknowledgements}

We thank Professor Dr H. G. Trüper (Bonn) and Professor J. P. Euzéby (Toulouse) for their help with the nomenclature.

\section{References}

Blümel, S., Mark, B., Busse, H.-J., Kämpfer, P. \& Stolz, A. (2001). Pigmentiphaga kullae gen. nov., sp. nov., a novel member of the family Alcaligenaceae with the ability to decolorize aerobically azo dyes. Int J Syst Evol Microbiol 51, 1867-1871.

Brosius, J., Palmer, M. I., Kennedy, P. J. \& Noller, H. F. (1978). Complete nucleotide sequence of a $16 \mathrm{~S}$ ribosomal RNA gene from Escherichia coli. Proc Natl Acad Sci U S A 75, 4801-4805.

Busse, H.-J. \& Auling, G. (1988). Polyamine pattern as a chemotaxonomic marker within the Proteobacteria. Syst Appl Microbiol 11, $1-8$.

Busse, H.-J. \& Stolz, A. (2004). Achromobacter, Alcaligenes and related genera. In The Prokaryotes: an Evolving Electronic Resource for the Microbiological Community, 3rd edn, release 3.17, 31 August 2004. New York: Springer Verlag (http://link.springer-ny.com/link/ service/books/10125/).

Busse, H.-J., El-Banna, T., Oyaizu, H. \& Auling, G. (1992) Identification of xenobiotic-degrading isolates from the beta subclass of the Proteobacteria by a polyphasic approach including 16S rRNA partial sequencing. Int J Syst Bacteriol 42, 19-26.

Coenye, T., Vancanneyt, M., Cnockaert, M. C., Falsen, E., Swings, J. \& Vandamme, P. (2003a). Kerstersia gyiorum gen. nov., sp. nov., a novel Alcaligenes faecalis-like organism isolated from human clinical samples, and reclassification of Alcaligenes denitrificans Rüger and Tan 1983 as Achromobacter denitrificans comb. nov. Int J Syst Evol Microbiol 53, 1825-1831.

Coenye, T., Vancanneyt, M., Falsen, E., Swings, J. \& Vandamme, P. (2003b). Achromobacter insolitus sp. nov. and Achromobacter spanius sp. nov., from human clinical samples. Int J Syst Evol Microbiol 53, 1819-1824.

Coenye, T., Vanlaere, E., Samyn, E., Falsen, E., Larsson, P. \& Vandamme, P. (2005). Advenella incenata gen. nov., sp. nov., a novel member of the Alcaligenaceae, isolated from various clinical samples. Int J Syst Evol Microbiol 55, 251-256.

Felsenstein, J. (1993). PHYLIP (phylogeny inference package), version 3.5c. Department of Genetics, University of Washington, Seattle, USA.

Foss, S., Heyen, U. \& Harder, J. (1998). Alcaligenes defragrans sp. nov., description of four strains isolated on alkenoic monoterpenes ((+)-menthene, alpha-pinene, 2-carene, and alpha-phellandrene) and nitrate. Syst Appl Microbiol 21, 237-244.

Kämpfer, P. \& Kroppenstedt, R. M. (1996). Numerical analysis of fatty acid patterns of coryneform bacteria and related taxa. Can J Microbiol 42, 989-1005.

Kämpfer, P., Steiof, M. \& Dott, W. (1991). Microbiological characterisation of a fuel-oil contaminated site including numerical identification of heterotrophic water and soil bacteria. Microb Ecol 21, 227-251.

Nörtemann, B., Baumgarten, J., Rast, H. G. \& Knackmuss, H.-J. (1986). Bacterial communities degrading amino- and hydroxynaphthalene-2-sulfonates. Appl Environ Microbiol 52, 1195-1202.

Russ, R., Müller, C., Knackmuss, H.-J. \& Stolz, A. (1994). Aerobic biodegradation of 3-aminobenzoate by Gram-negative bacteria involves intermediate formation of 5-aminosalicylate as ring-cleavage substrate. FEMS Microbiol Lett 122, 137-143.

Stolz, A. (1989). Metabolismus von Amino- und Hydroxysalicylsäuren durch einen Bakterienstamm der Gattung Pseudomonas. PhD thesis, Universität Stuttgart.

Stolz, A. \& Knackmuss, H.-J. (1993a). Bacterial metabolism of 5aminosalicylic acid: enzymatic conversion to L-malate, pyruvate and ammonia. J Gen Microbiol 139, 1019-1025.

Stolz, A. \& Knackmuss, H.-J. (1993b). Degradation of 2,4dihydroxybenzoate by Pseudomonas sp. BN9. FEMS Microbiol Lett 108, 219-224.

Stolz, A., Nörtemann, B. \& Knackmuss, H.-J. (1992). Bacterial metabolism of 5-aminosalicylic acid. Initial ring cleavage. Biochem $J$ 282, 675-680.

Vandamme, P., Heyndrickx, M., Vancanneyt, M., Hoste, B., De Vos, P., Falsen, E., Kersters, K. \& Hinz, K.-H. (1996). Bordetella trematum sp. nov., isolated from wounds and ear infections in humans, and reassessment of Alcaligenes denitrificans Rüger and Tan 1983. Int J Syst Bacteriol 46, 849-858.

Willems, A., Gilhaus, H., Beer, W., Mietke, H., Gelderblom, H. R., Burghardt, B., Voigt, W. \& Reissbrodt, R. (2002). Brackiella oedipodis gen. nov., sp. nov., Gram-negative, oxidase-positive rods that cause endocardiditis of cotton-topped tamarin (Saguinus oedipus). Int J Syst Evol Microbiol 52, 179-186.

Yabuuchi, E., Kosako, Y., Yano, I., Hotta, H. \& Nishiuchi, Y. (1995). Transfer of two Burkholderia and an Alcaligenes species to Ralstonia gen. nov.: proposal of Ralstonia pickettii (Ralston, Palleroni and Doudoroff 1973) comb. nov., Ralstonia solanacearum (Smith 1896) comb. nov. and Ralstonia eutropha (Davis 1969) comb. nov. Microbiol Immunol 39, 897-904.

Yabuuchi, E., Kawamura, Y., Kosako, Y. \& Ezaki, T. (1998). Emendation of genus Achromobacter and Achromobacter xylosoxidans (Yabuuchi and Yano) and proposal of Achromobacter ruhlandii (Packer and Vishniac) comb. nov., Achromobacter piechaudii (Kiredjian et al.) comb. nov., and Achromobacter xylosoxidans subsp. denitrificans (Ruger and Tan) comb. nov. Microbiol Immunol 42, 429-438. 